\title{
Morphometric analysis of Squalius namak Khaefi et al. 2016 in Khaznagh and Ghare-Chai rivers
}

\author{
Atta Mouludi-Saleh* and Yazdan Keivany \\ Department of Natural Resources (Fisheries Division), Isfahan University of Technology, Isfahan \\ 841568311, Iran \\ * Corresponding author (atta.moulodi@gmail.com)
}

https://orcid.org/0000-0002-0939-0901

\begin{abstract}
The Namak Chub, Squalius namak, is a newly described cyprinid from Namak basin of Iran, but there is little information on its body variations. To investigate the population differences, fifty-two specimens ( 37 from Khaznagh and 15 from Ghare-Chai) of Squalius namak (Teleostei: Cyprinidae) were captured by seine net during the summer of 2010. After anesthetizing, specimens were transferred to Ichthyology Museum (IUT-IM) for further studies. The specimens were photographed from their left side and 13 landmarks were defined on the photos in Tpsdig2 software. Procrustes analysis (GPA) was performed to eliminate non-shaped effects, the size, direction and position of the specimens. Principal Component Analysis (PCA), Discriminant Function Analysis (DFA) and wireframe graph were used to analyze these populations. The results of this study showed a significant difference between the two populations. The major differences observed were the depth of the body, head size and the position of the mouth. The Ghare-Chai River population has a greater body depth and smaller head length. Further, the position of the mouth in the Khaznagh river population was more inferior compared to the Ghare-Chai River population.
\end{abstract}

Keywords: Squalius namak, body shape, landmarks, Procrustes analysis, DFA

\section{INTRODUCTION}

Studying flexibility of morphology among individuals of the same species could facilitate understanding of environmental effects on different populations (Mouludi-Saleh et al. 2017; Banimasani et al. 2018). Fish populations in different environmental conditions, show different morphological forms (Mouludi-Saleh et al. 2018a). Fish exhibit high variations in morphological traits at both levels within and between the populations and other species, and are highly susceptible to environmental changes due to the development of morphological changes (Stearns 1993; Keivany et al. 2016). Fish show a wide range of intra-thoracic variations that are important ecologically and evolutionally. Without physical barriers to genetic flow and fish migration, there is little opportunity for local adaptation that can lead to population uniformity (Robinson and Wilson 1994). Body shape is one of the important features of fish biology which can directly affect the nutritional efficiency, reproduction and survival in aquatic environments (Guill et al. 2003). Geometric morphometric is defined as a statistical study of biological shapes and shape variations among different populations and it allows the characterization of growth trajectory and the visualization of allometric growth. Many reports on applications of geometric morphometric method in different biological fields including fisheries are available (Eagderi et al. 2013; Keivany and Arab 2017; Banimasani et al. 2018; Ghorbani-Ranjbari and Keivany 2018a, 2018b; Tajik and Keivany 2018a, 2018b).This method offers powerful analytical and graphical tools for the quantification and visualization of morphological variation within and among organisms, both in animals and plants (Alberch et al. 1979).

Based on the latest checklist of freshwater fishes of Iran, 288 species in 107 genera, 28 families, 22 
orders and 3 classes reported from different Iranian basins (Esmaeili et al. 2017). The most diverse order is Cypriniformes (171 species, 59\%). Four species from the genus Squalius have identified in Iranian basins, including $S$. turcicus De Filippi 1865, from the Caspian and Urmia Lake basins, S. namak Khaefi et al. 2016 from Namak lake basin, S. berak Heckel 1843 and S. lepidus Heckel 1843 from Tigris basin (Esmaeili et al. 2017). Since this species has recently been recognized in Iranian Inland waters and has not been studied, the comparison of the morphology of this species is important. This study was designed to show body shape differences between the populations studied in the two habitats.

\section{MATERIALS AND METHODS}

\section{Study area and sampling}

Lake Namak basin of Iran is located between Qom, Isfahan and Semnan provinces. The known rivers of this basin can be noted to Khaznagh and GhareChai. In order to Fifty two immature specimens of Squalius namak were collected from two rivers of Namak Lake basin; Khaznagh River, 49 $21^{\prime \prime} \mathrm{N}$; $35^{\circ} 5^{\prime \prime} \mathrm{E}$ and Ghare-Chai, $50^{\circ} 2^{\prime \prime N}$; 34 $4^{\circ} 53^{\prime \prime} \mathrm{E}$ (Fig. 1) using a seine net $(15 \mathrm{~m}$ long, $2 \mathrm{~m}$ width and $5 \mathrm{~mm}$ mesh size) (37 specimens from Khaznagh and 15 specimens from Ghare-Chai) During the summer of 2009- 2010. After anesthetizing the specimens in
$1 \%$ clove oil solution and fixing in $10 \%$ neutralized formalin, they were transferred to the Isfahan University of Technology Ichthyology Museum (IUT-IM) for further studies. In the laboratory, the left sides of the specimens were photographed using a Canon digital camera (8 MP). Thirteen landmarks on two-dimensional images were selected using Tpsdig2 (Fig. 2, Table 1). They were then overlaid to extract the form data and remove non-form data such as size, position and direction by Procrustes Analysis (GPA). Body shape data were analyzed using multivariate analyzes; Principal Component Analysis (PCA) and Discriminant function analysis (DFA) in PAST and Morpho J software.

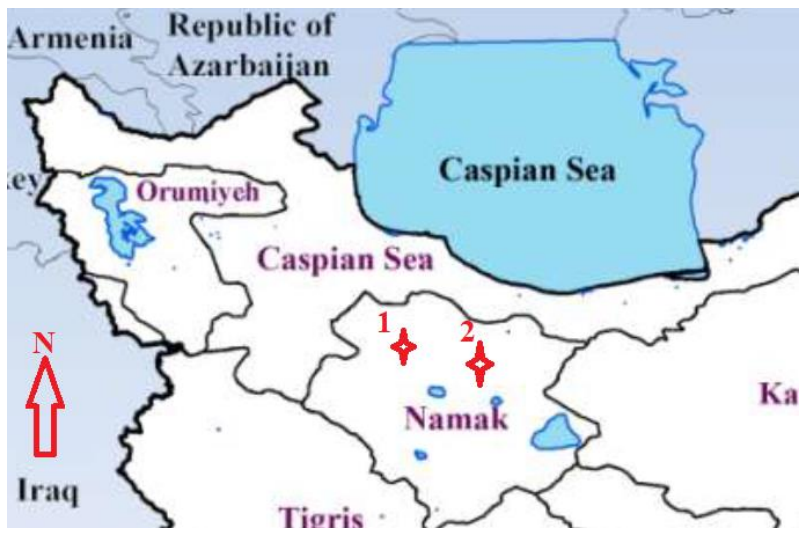

Fig. 1 Sampling sites of Squalius namak (1: Khaznagh, 2: Ghare-Chai) in Iran

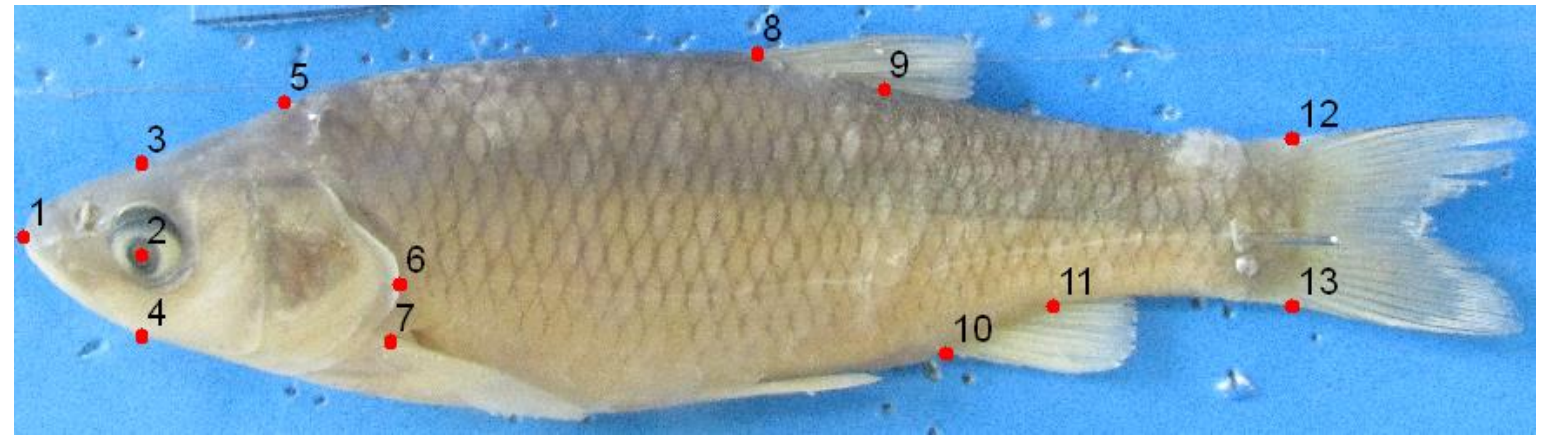

Fig. 2 The 13 defined landmark points for extracting the body shape data in Squalius namak 
Table1 List of landmark points for extracting the body shape data in Squalius namak

\begin{tabular}{ll}
\hline Landmark Number & Landmark \\
\hline 1 & snout tip \\
2 & center of eye \\
3 & dorsal edge of the head perpendicular to the center of eye \\
4 & ventral edge of the head perpendicular to the center of eye \\
5 & boundary between smooth and scaly skin \\
6 & terminal operculum \\
7 & superior insertion of the pectoral fin \\
8 & superior insertion of the dorsal fin \\
9 & posterior end of the dorsal fin base \\
10 & anterior ends of the anal fin base \\
11 & posterior ends of the anal fin base \\
12 & poster dorsal end of caudal peduncle at its connection to caudal fin \\
13 & poster ventral end of caudal peduncle at its connection to caudal fin \\
\hline
\end{tabular}

\section{RESULTS}

Based on the PCA analysis, 27 main factors were extracted and three components were higher than the cutoff point of Jollieff line (Fig. 3). These three principal components $(\mathrm{PC} 1=47.32 \%, \mathrm{PC} 2=$ $15.23 \%$ and $\mathrm{PC} 3=9.32 \%$ ) accounted for $72 \%$ of the total variance. The principal component scores of two populations were not overlapping (Fig. 4). The major difference observed in the positive side of the two principal components included snout (LM1) and anal fin repositioning $(\mathrm{LM} \mathrm{9,10)}$ in the direction of PC1 and ventral (LM 6, 7), anal (LM 9, 10) and cadual fin (LM 12,13) repositioning and reduction of the body depth (LM 7, 8). The results of Discriminant Function analysis (DFA) indicated significant differences between the two populations based on morphological characteristics (Fig. 5).

Comparison of the body shape of these two populations using wireframe diagram revealed that they differ in the body depth, the position of the snout and anal fin (Fig. 6).

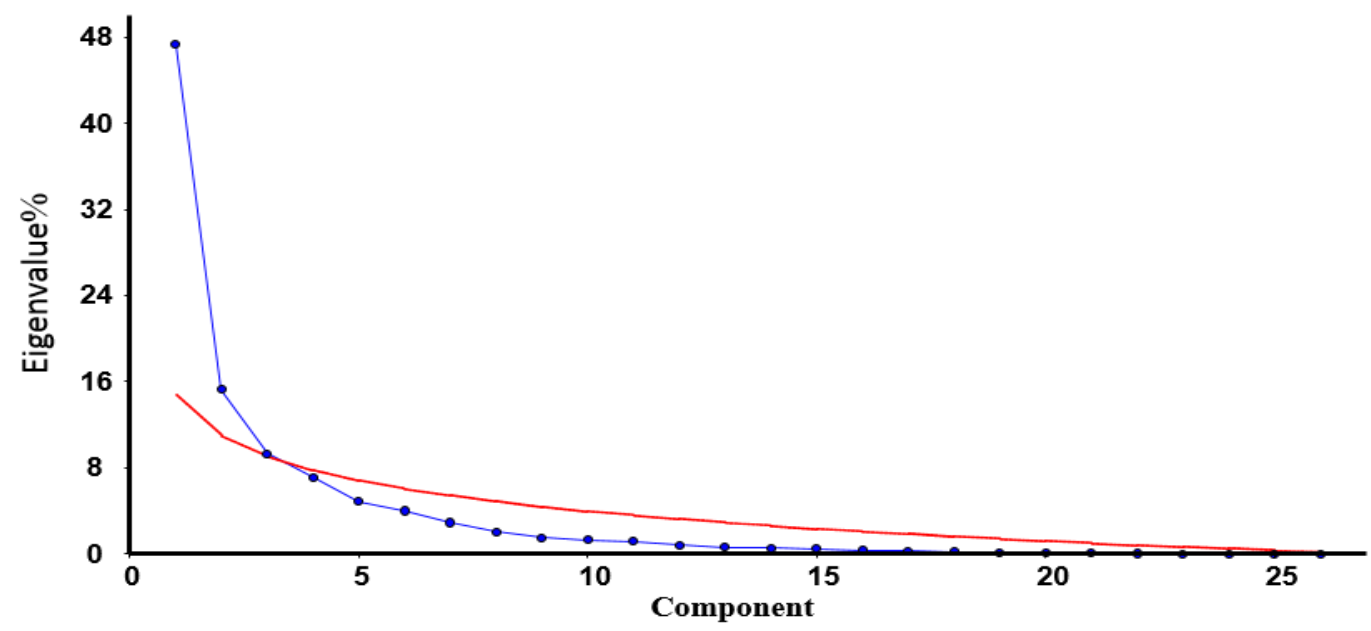

Fig. 3 Percent Eigenvalue of principal component analysis of Squalius namak populations and the Joliffe cut-off point (red line) 


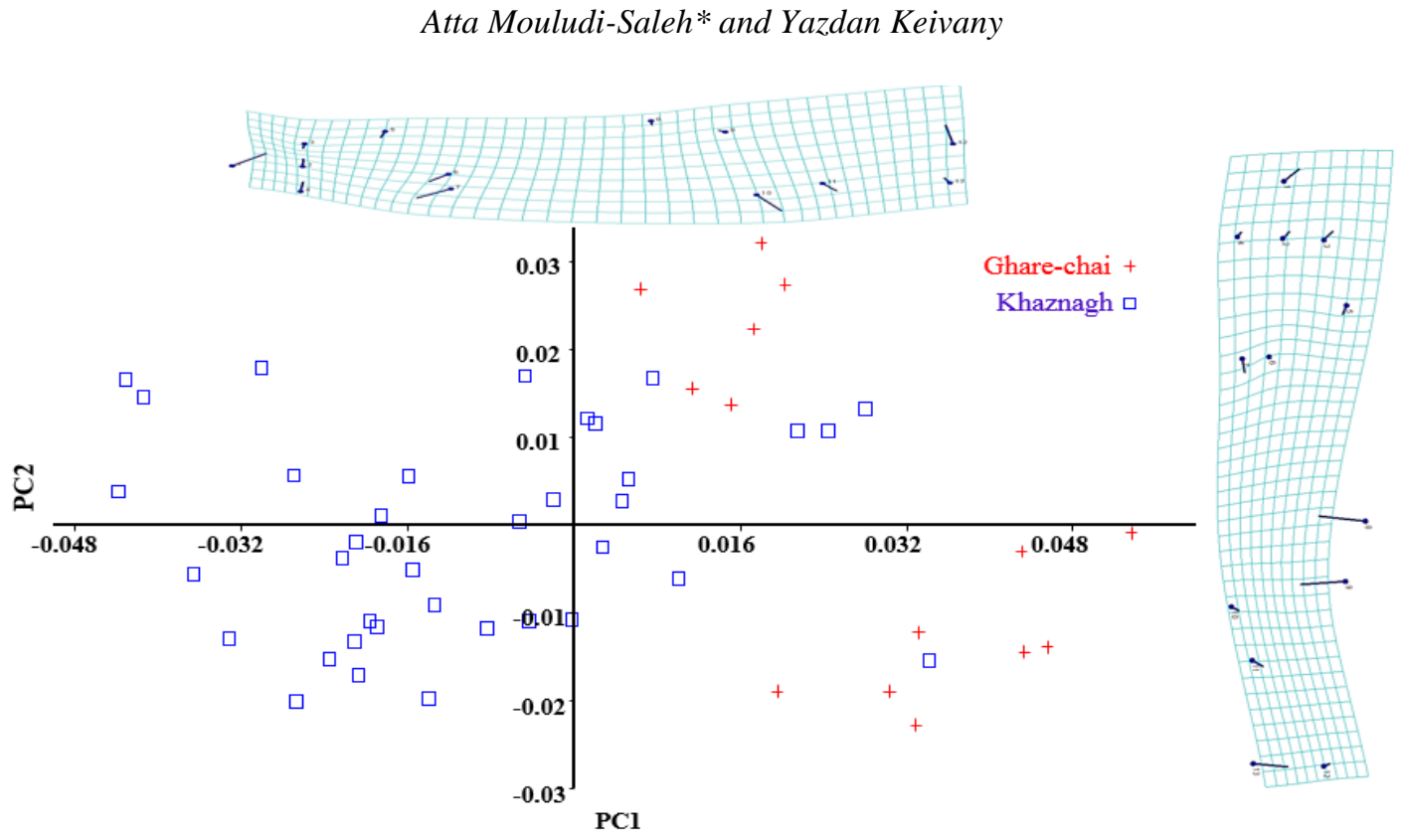

Fig. 4 Principal components analysis of body shape for Squalius namak populations in Namak Lake Rivers

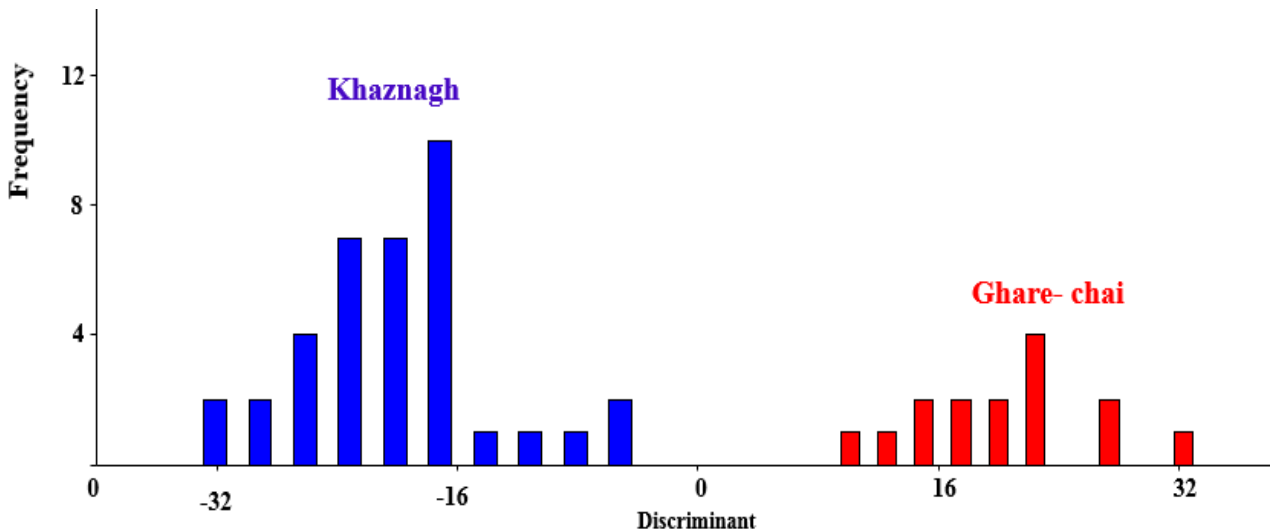

Fig. 5 Results of the discriminant function analysis (DFA) of two populations of S. namak

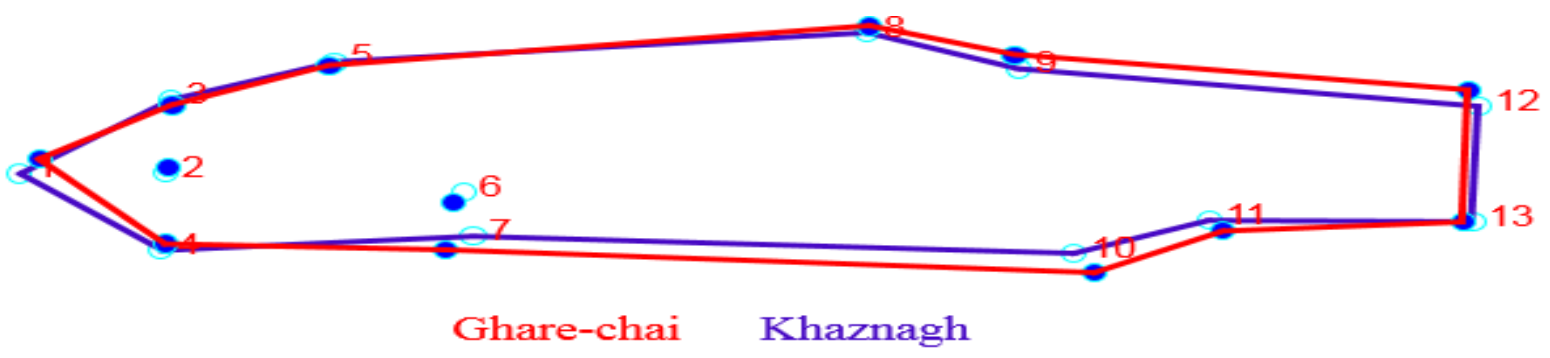

Fig. 6 Consensus body shape graph of two populations of Squalius namak 


\section{DISCUSSION}

The results of the present study showed significant morphological differences between populations of Squalius namak in Khaznagh and Ghare-Chai rivers. Different morphological characteristics of populations can be due to either genetic differentiation or phenotypic plasticity in response to environmental parameters of their habitat (Eagdari et al. 2013; Jalili et al. 2015; Razavipour et al. 2015; Keivany and Ghorbani-Ranjbari 2017). Environmental factors through natural selection can increase the efficiency of a phenotype among the members of a population and thus is led to morphological isolation in different habitats (Smith and Skulason 1996; Keivany and Arab 2017). Khaznagh River population has a longer snout and a shallower body and cadual peduncle relative to Ghare-Chai River population. The abdominal position of mouth in Khaznagh population may indicate that this population feed on deeper parts (Mouludi-Saleh et al. 2017). Similar results were found in Squalius turcicus in South-eastern Caspian Sea (Mouludi-Saleh et al. 2018b).

Body shape and fin forms are important traits that are influenced by environmental conditions of rivers (Douglas and Matthews1992; Tajik and Keivany 2018a, 2018b). Hence, by studying these traits, we can predict what conditions govern a habitat (Chan 2001). The Khaznagh River population has a shallower body, which means that the fish have adapted to the flow through the formation of a tufted and stretched structure (Barlow 1961). The small size of the body and the stretched body shape have also been proven in fish inhabiting rivers with higher flow rates in the presence of lower flow (Paez et al. 2008). It could be concluded that Squalius namak is a morphologically variable species that lives in variable environments (Mouludi-Saleh et al. 2017). This adaptation in aquatic ecosystems is a result of having to compromise with hydrodynamic forces to save energy during bio-related behaviors. Morphological variability is not always indicative of environment and genetic differences of the populations might be involved. Thus, it is suggested to examine the populations with genetic and molecular methods.

\section{ACKNOWLEDGEMENTS}

We would like to thank Dr. M. Nasri, Mr. A. Nezamoleslami, Mr. S. Asadollah, Dr. S. Dorafshan, and Mr. A. Mirzaei for their help in field work. Mr. Mazaher Zamani-Faradonbe is gratefully appreciated for his help in the laboratory work. This research was financially supported by Isfahan University of Technology.

\section{REFERENCES}

Alberch, P., S.J. Gould, G.F. Oster and D.B. Wake 1979. Size and shape in ontogeny and phylogeny. Paleobiology 5(3): 296-317.

Banimasani, M., Y. Keivany and E. Ebrahimi 2018. Comparative study of Capoeta barroisi populations in Qomrud, Kor and Sheldon rivers using meristic and geometric morphometric data. Journal of Animal Environment 10(1):145-152.

Barlow, G.W. 1961. Social behavior of the desert pupfish, Cyprinodon macularius, in the field and in the aquarium. American Midland Naturalist 65: 339-359. DOI: $10.2307 / 2422959$.

Chan, M.D. 2001. Fish ecomorphology: predicting habitat preferences of stream fishes from their body shape. Ph.D. thesis in fisheries and wildlife sciences at the faculty of the Virginia Polytechnic Institute and State University.

Douglas, M.E. and W.J. Matthews 1992. Does morphology predict ecology? Hypothesis testing within a freshwater stream fish assemblage. Oikos 65: 213-224. DOI: 10.2307/3545012.

Esmaeili, H.R., H. Mehraban, K. Abbasi, Y. Keivany and B.W. Coad 2017 Review and updated checklist of freshwater fishes of Iran: Taxonomy, distribution and conservation status. Iranian Journal of Ichthyology 4(Suppl. 1): 1114. DOI: 10.22034/iji.v4iSuppl.\%201.220.

Eagderi, S., E. Esmaeilzadegan and A. Madah 2013. Body shape variation in riffle minnows (Alburnoides eichwaldii De Filippii, 1863) populations of Caspian Sea basin. Taxonomy and Biosystematics Journal 5(14): 1-8.

Ghorbani-Ranjbari, Z. and Y. Keivany 2018a. Geometric morphometric comparison of three populations of Barilius mesopotamicus (Berg 1932) in Jarrahi River basin. Journal of Aquatic Ecology (In Press). 
Ghorbani-Ranjbari, Z. and Y. Keivany 2018b. Geometric morphometric comparison of Barilius mesopotamicus (Berg 1932) populations in Bushehr basin. Journal of Animal Researches (In press).

Guill, J.M., C.S. Hood and D.C. Heins 2003. Body shape variation within and among three species of darters (Perciformes: Percidae). Ecology of Freshwater Fish 12(2): 134-140.

Jalili, P., S. Eagderi and Y. Keivany 2015. Body shape comparison of Kura bleak (Alburnus filippii) in Aras and Ahar-Chai rivers using geometric morphometric approach. Research in Zoology 5(1): 20-24. DOI: 10.1034/j.16000633.2003.00008.x

Keivany, Y. and M. Arab 2017. Geometric morphometric comparison of trout barb, Capoeta trutta (Teleostei: Cyprinidae) in the Tigris River basin. Iranian Journal of Ichthyology 4(3): 220230. DOI: 10.22034/iji.v4i3.227.

Keivany, Y. and Z. Ghorbani-Ranjbari 2017. Geometric morphometric comparison of Mesopotamian minnow (Barilius mesopotamicus Berg 1932) populations in Iran. Journal of Exploitation and Aquaculture 6(1): 113.

Keivany, Y., M. Nasri, K. Abbasi and A. Abdoli 2016a. Atlas of Inland Water Fishes of Iran. Iran Department of Environment Press, Tehran, Iran. 218p.

Keivany, Y., S.M.A Mousavi, S. Dorafshan and M. Zamani-Faradonbe 2016b. Morphological variations of Alburnus mossulensis Heckel, 1843 populations in the Tigris tributaries of the Persian basin in Iran (Teleostei: Cyprinidae). Iranian Journal of Ichthyology 3(3): 190-202. DOI: 10.7508/iji.2016.02.

Khaefi, R., H.R. Esmaeili, G. Sayyadzadeh, M.F. Geiger and J. Freyhof 2016. Squalius namak, a new chub from Lake Namak basin in Iran (Teleostei: Cyprinidae). Zootaxa 4169(1): 145159. DOI: 10.11646/zootaxa.4169.1.7.

Mouludi-Saleh, A., Y. Keivany and S.A.H. Jalali 2017. Geometric Morphometric Comparison of Namak Chub (Squalius namak, Khaefi et al., 2016) in Rivers of Lake Namak Basin of Iran. Research in Zoology 7(1): 1-6. DOI: 10.5923/j.zoology.20170701.01.
Mouludi-Saleh, A., Y. Keivany and S.A.H. Jalali 2018a. Comparison of meristic traits in Transcaucasian chub (Squalius turcicus De Filippi, 1865) from Caspian Sea basin. International Journal of Aquatic Biology 6(1): 814. DOI: 10.22034/ijab.v6i1.317.

Mouludi-Saleh, A., Y. Keivany, S.A.H. Jalali and M. Zamani-Faradonbe 2018b. Morphological flexibility of Transcaucasian Chub (Squalius turcicus De Filippi, 1865) in South-eastern Caspian Sea basin using geometric morphometric. Journal of Animal Environment (In press).

Paez, D.J., R. Hedger, L. Bernatchez and J.J. Dodson 2008. The morphological plastic response to water current velocity varies with age and sexual state in juvenile Atlantic salmon, Salmo salar. Freshwater biology 53(8): 15441554. DOI: 10.1111/j.1365-2427.2008.01989.x.

Razavipour, P., S. Eagderi, H. Poorbagher, A. Javanshir Khooi and Y. Keivany 2015. Phenotypic plasticity of the Tuini fish, Capoeta damascina (Actinopterygii: Cyprinidae) populations in Iranian part of Tigris basin using geometric morphometric approach. Journal of Animal Research 28(2): 170-179.

Robinson, B.W. and D.S. Wilson 1994. Character release and displacement in fishes: a neglected literature. The American Naturalist 144(4): 596627. DOI: $10.1086 / 285696$.

Smith, T.B. and S. Skúlason 1996. Evolutionary significance of resource polymorphisms in fishes, amphibians, and birds. Annual Review of Ecology and Systematics 27(1): 111-133. DOI: 10.1146/annurev.ecolsys.27.1.111.

Stearns, S.C. 1983. A natural experiment in lifehistory evolution: field data on the introduction of mosquito fish (Gambusia affinis) to Hawaii. Evolution 37: 601-617. DOI: 10.1111/j.15585646.1983.tb05577.x.

Tajik, Z. and Y. Keivany 2018a. Body shape comparison of Urmia bleak populations, Alburnus atropatenae. Journal of Animal Environment (In press).

Tajik, Z. and Y. Keivany 2018b. Comparative biometry of the Urmia bleak populations, Alburnus atropatenae. Journal of Animal Research (In press). 